\title{
$\mathrm{GaN} \mathrm{HEMT} \mathrm{Die}$ 를 이용한 $\mathrm{Ku}-$ 대역 전력 증폭기 설계 및 제작
}

\section{Design and Fabrication of Ku-Band Power Amplifier Using GaN HEMT Die}

\author{
김상훈 · 김보기·최진주 · 정병구 ${ }^{*}$ 태현식* \\ Sang-Hoon Kim $\cdot$ Bo-Ki Kim $\cdot$ Jin-Joo Choi $\cdot$ Byeoung-Koo Jeong* $\cdot$ Hyun-Sik Tae* \\ 요 약
}

본 논문은 GaN(Gallium Nitride) HEMT(High Electron Mobility Transistor) die를 이용하여 Ku-대역 전력 증폭기 설계, 제 작 그리고 실험 결과에 대해 기술하였다. 저비용으로 $\mathrm{Ku}$-대역 전력 증폭기를 설계하기 위하여 고가의 알루미나 회로 기판 제작 대신 PCB(Printed Circuit Board)를 이용하여 입/출력단 정합 회로를 이용하였다. 측정 결과로는 펄스 모드로 동작시켰을 때 $14.8 \mathrm{GHz}$ 에서 $42.6 \mathrm{dBm}$ 의 출력 전력, $37.7 \%$ 드레인 효율 그리고 $7.9 \mathrm{~dB}$ 의 선형 이득을 얻었다. $\mathrm{CW}$ (Continuous Wave) 실험 결과로는 $39.8 \mathrm{dBm}$ 의 출력 전력, $24.1 \%$ 의 드레인 효율 그리고 $7.2 \mathrm{~dB}$ 의 선형 이득을 얻을 수 있었다.

\section{Abstract}

This paper presents a design and fabrication of Ku-band power amplifier using Gallium Nitride High Electron Mobility Transistor (GaN HEMT) die. In order to fabricate the low-cost Ku-band power amplifier, a Printed Circuit Board(PCB) was used for input/output matching circuits instead of manufacturing process to use an expensive substrate. The measured output power is $42.6 \mathrm{dBm}$, the drain efficiency is $37.7 \%$ and the linear gain is $7.9 \mathrm{~dB}$ under pulse operation at the frequency of $14.8 \mathrm{GHz}$. Under the continuous wave(CW) test, the output power is $39.8 \mathrm{dBm}$, the drain efficiency is $24.1 \%$ and the linear gain is $7.2 \mathrm{~dB}$.

Key words: Ku-Band, GaN HEMT Die, Low-Cost, Power Amplifier

\section{I. 서 론}

$\mathrm{Ku}$-대역 고출력 전력 증폭기는 무선 통신 시스템에 다 양하게 사용되어지고 있다. $\mathrm{Ku}$-대역에서 대부분의 고출 력 전력 증폭기는 TWT(Traveling Wave Tube), 클라이스 트론 및 자이로트론 등과 같은 진공 전력 증폭기가 주를 이루고 있다. 이러한 증폭기들은 여전히 수백 수킬로 와
트급 고출력을 위해서 이용되고 있다. 반도체 소자를 이 용한 반도체 전력 증폭기(Solid-State Power Amplifier: SS$\mathrm{PA})$ 는 신뢰성, 크기의 소형화 및 저전압 동작 등과 같은 장점이 있다 ${ }^{[1]}$. 이러한 이유들로 $\mathrm{Ku}$-대역에서도 $\mathrm{GaN} \mathrm{HE}$ MT bare chip을 이용하여 고출력 반도체 전력 증폭기가 활발하게 연구되고 있다 ${ }^{[2] ~[5] . ~}$

본 논문에서는 $\mathrm{Ku}$-대역 고출력 반도체 전력 증폭기를

\footnotetext{
「이 연구는 2013년도 삼성탈레스 연구비의 지원으로 연구되었음.

광운대학교 전파공학과(Department of Wireless Communications Engineering, Kwangwoon University) *삼성탈레스(Samsung Thales)

• Manuscript received February 4, 2014 ; Revised March 11, 2014 ; Accepted April 16, 2014. (ID No. 20140204-016)

· Corresponding Author: Jin-Joo Choi (e-mail: jinchoi@kw.ac.kr)
} 
$\mathrm{PCB}$ 를 이용하여 입/출력단 정합 회로를 설계하여 저비용 으로 제작을 하고, 실험 결과를 얻은 것에 대해 기술하였다.

\section{II. 설계 및 제작}

$\mathrm{Ku}$-대역 전력 증폭기 설계를 위하여 Cree사 $25 \mathrm{~W}$ 급 CGHV1J025D GaN HEMT die를 선정하였다. 그림 1은 본 논문에 사용되어진 GaN HEMT die의 사진을 나타낸다. 이 소자는 $0.25 \mathrm{um}$ 게이트 길이를 가지는 GaN-on-silicon carbide( $\mathrm{SiC}) \mathrm{HEMT}$ 이다.

표 1은 Cree사 CGHV1025D의 특성을 나타낸다. $\mathrm{DC}$ 에 서부터 $18 \mathrm{GHz}$ 까지 사용이 가능하며, 드레인 전압이 40 $\mathrm{V}$ 일 때 $15 \mathrm{GHz}$ 의 주파수에서 $43.8 \mathrm{dBm}$ 의 포화 출력 전 력, $7 \mathrm{~dB}$ 의 전력 이득과 $52 \%$ 의 드레인 효율을 낼 수 있 다고 데이터 시트상에 명시되어 있다.

설계는 Agilent Advanced Design System(ADS)와 Ansoft 사의 High Frequency Structure Simulation(HFSS)을 병행적 으로 사용하여 진행하였다. 우선, 소자의 바이어스 조건 과 설계 주파수 대역에서 입/출력단 최적의 임피던스를

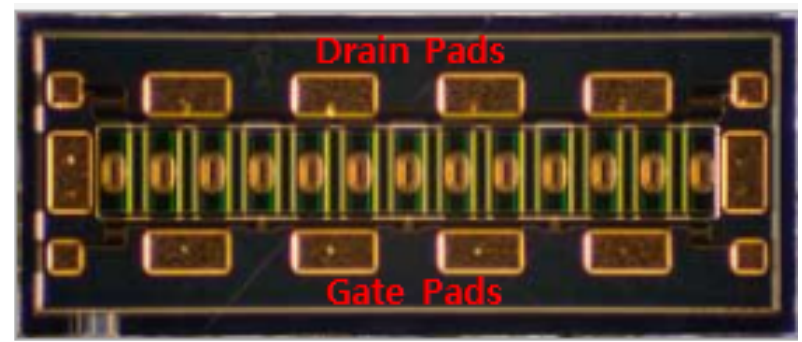

그림 1. Cree사 GaN HEMT die CGHV1J025D 형상

Fig. 1. GaN HEMT die Cree's CGHV1J025D.

표 1. CGHV1J025D 소자의 제원

Table 1. Specification of CGHV1J025D.

\begin{tabular}{|c|c|}
\hline 성능 변수 & 값 \\
\hline 사용 가능 주파수 & $\mathrm{DC}-18 \mathrm{GHz}$ \\
\hline 포화 출력 전력 & $43.8 \mathrm{dBm} @ 15 \mathrm{GHz}$ \\
\hline 전력 이득 & $7 \mathrm{~dB} @ 15 \mathrm{GHz}$ \\
\hline 드레인 효율 & $52 \% @$ Psat \\
\hline 드레인 전압 & $40 \mathrm{~V}$ \\
\hline 크기 & $0.80 \times 1.92 \times 0.10 \mathrm{~mm}$ \\
\hline
\end{tabular}

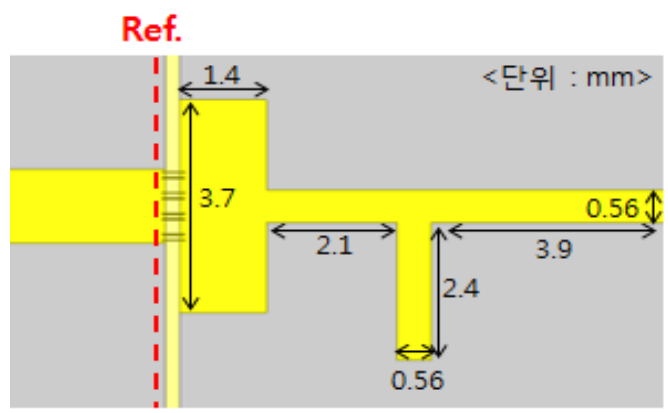

(a) 입력단

(a) Input

Ref.

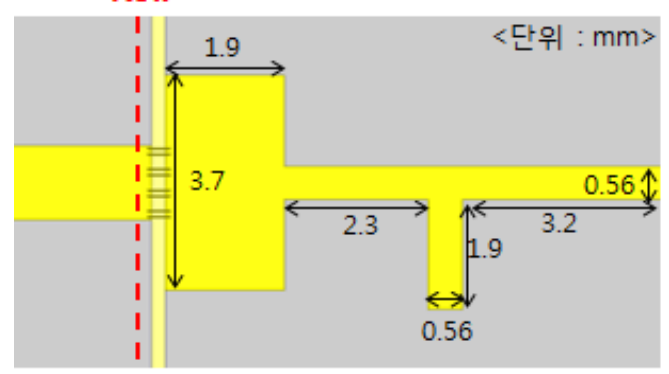

(b) 출력단

(b) Output

그림 2. $\mathrm{HFSS}$ 를 이용한 정합 회로

Fig. 2. Matching circuits using HFSS.

찾기 위해 Cree사에서 제공해 준 비선형 모델과 $\mathrm{ADS}$ 시 뮬레이션 코드를 이용하여 소스/로드-풀 시뮬레이션을 수 행하였다. $15 \mathrm{GHz}$ 에서 드레인 전압 $40 \mathrm{~V}$, 바이어스 전류 가 $180 \mathrm{~mA}$ 일 때의 최적의 소스 임피던스는 $0.645-j 1.287$ $\Omega$ 이고, 로드 임피던스는 1.346-j4.605 $\Omega$ 이다. ADS 소스/ 로드-풀 시뮬레이션에서 얻은 결과를 바탕으로 Ansoft사 의 High Frequency Structure Simulation(HFSS)을 통해 본딩 와이어 효과를 포함하여 그림 2와 같이 입/출력단 정합 회로를 설계하였다.

그림 3은 $\mathrm{HFSS}$ 를 이용하여 설계한 소스 및 로드 임피 던스의 위치를 보여준다. 소스 임피던스는 $0.77-j 1.287 \Omega$ 이고, 로드 임피던스는 $1.42+j 4.8 \Omega$ 이다.

앞에서 $\mathrm{ADS}$ 시뮬레이션 코드를 통해 얻어낸 소스 및 로드 임피던스와 완전히 동일하지는 않지만, $\mathrm{ADS}$ 시뮬레 이션 코드에서 얻은 임피던스 점과 최대한 근처에 위치 하게 설계하였다. HFSS 시뮬레이션에서 얻은 입/출력단 


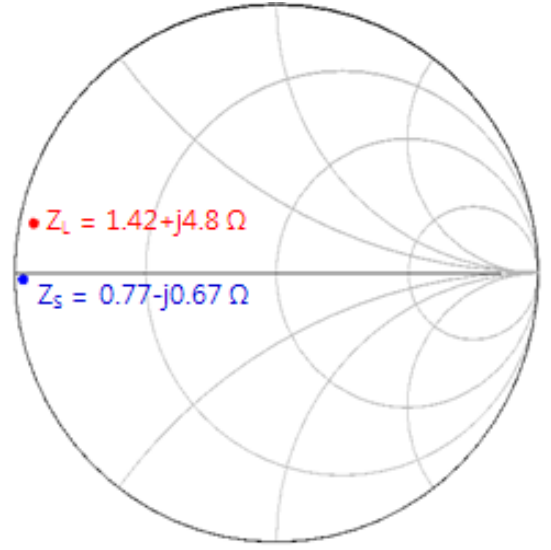

그림 3. 소스 및 로드 임피던스 시뮬레이션 결과(HFSS)

Fig. 3. The simulation results of source \& load impedance. (HFSS).

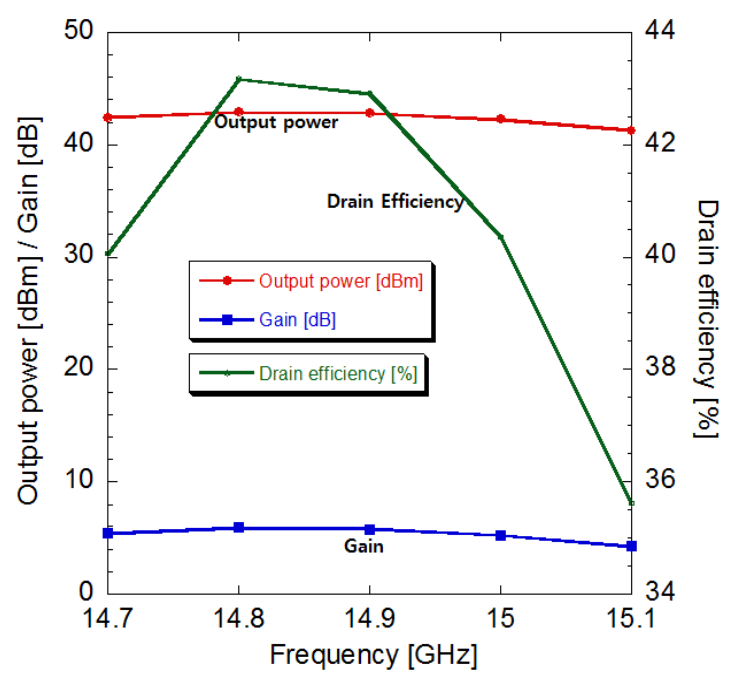

그림 4. 대신호 시뮬레이션 결과(ADS)

Fig. 4. The simulation results of the large signal(ADS).

임피던스 결과를 $s 2 p$ 파일로 추출하여 ADS 시뮬레이션 코드에 심어서 출력 전력, 전력 이득 및 드레인 효율을 예 측해 보았다. 그림 4와 같이 $\mathrm{Ku}$-대역 $14.8 \mathrm{GHz}$ 에서 42.9 $\mathrm{dBm}$ 출력 전력, $5.9 \mathrm{~dB}$ 전력 이득 및 $43.2 \%$ 의 드레인 효 율을 얻을 수 있었다.

고주파 대역에서는 스터브의 라인 폭 및 길이에 따른 임피던스의 변화가 매우 민감하고, 설령 시뮬레이션과 동 일하게 설계를 하여 제작을 하더라도 본딩 와이어 길이 및 $\mathrm{PCB}$ 제작 시 생기는 오차로 인해 임피던스가 틀어질
가능성이 있기 때문에 입/출력 정합 회로 기판 제작 시 튜닝 패드를 만들어서 측정 시 임피던스 변화를 측정할 수 있도록 제작을 하였다. 위에서 언급한 발생 가능한 오 차들 중에서 실제 전력 증폭기를 제작할 때 제작 오차가 발생할 확률이 가장 큰 본딩 와이어 길이에 따른 영향을 HFSS 시뮬레이션 코드를 이용하여 분석해 보았다. 본딩 와이어 길이에서 오차 발생 확률이 가장 큰 이유는 $\mathrm{GaN}$ bare chip에서 마이크로스트립 라인으로 본딩 와이어를 연결할 때, 수동으로 연결을 해야 하기 때문에 아무리 정 확하게 맞춘다고 하여도 시뮬레이션에서 설계한 길이와 차이가 날 수 있기 때문이다. 그리하여 직경이 $1 \mathrm{mil}$ 인 본 딩 와이어를 길이에 따른 임피던스 변화를 시뮬레이션 코드를 통해 살펴보았다.

그림 5 와 같이 본딩 와이어 기준점을 설계하여 임의의 정합 회로에서의 임피던스 점을 확인하고, 기준보다 0.1 $\mathrm{mm}$ 씩 변화를 주어가며 임피던스가 어떻게 변화하는지 살펴보았다. 그림 6에서 확인할 수 있듯이, 본딩 와이어 가 $0.1 \mathrm{~mm}$ 씩 증가할 때마다 위상이 약 6 씩 증가하는 경 향을 확인하였다. 그리하여 입/출력단 정합 회로를 제작 하기에 앞서 시뮬레이션을 통해 튜닝 패드를 이용하여 임피던스가 어떻게 변화하는지 경향을 파악한 후 실제 전력 증폭기를 제작한다. 그림 7이 실제 제작된 전력 증 폭기이다. 제작된 입/출력단 정합 회로 기판은 유전율 3.5 인 TACONIC사 RF35A2이며, 기판 두께는 10 mils 기판을 사용하여 제작하였다. 그리고 마이크로스트립 라인 폭과 길이를 변화시킬 수 있는 튜닝 패드를 설계하여 제작하 였다. 전력 증폭기에 사용된 캐리어는 $\mathrm{GaN}$ bare die에서

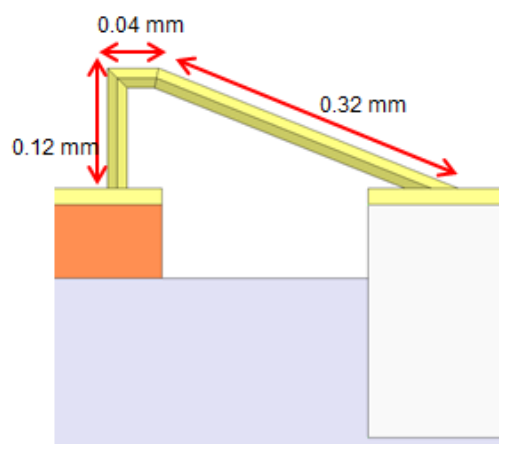

그림 5. 본딩 와이어 설계(HFSS)

Fig. 5. The design of the bonding wire(HFSS). 


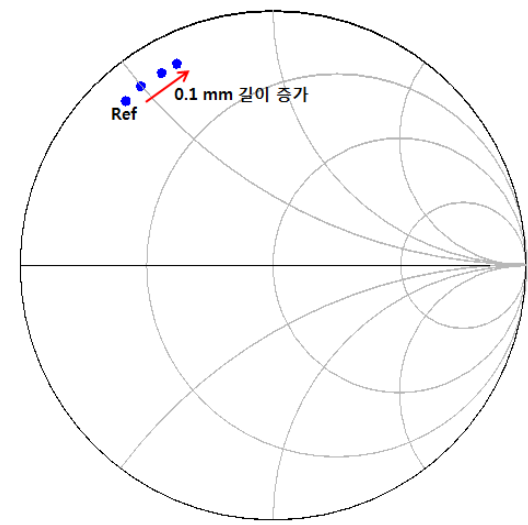

그림 6. 본딩 와이어 길이에 따른 영향(HFSS)

Fig. 6. The effects of different bonding wire length(HFSS).

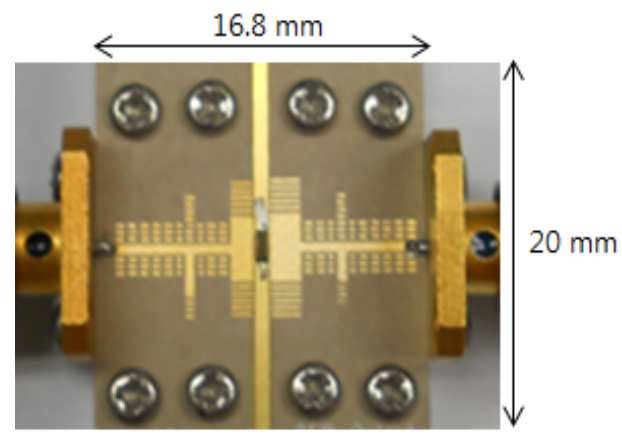

그림 7. 제작된 $\mathrm{Ku}$-대역 전력 증폭기 사진

Fig. 7. The photograph of the fabricated Ku-band power amplifier.

발생하는 열을 효과적으로 배출하기 위해 $15: 85 \%$ 비율 로 합금된 $\mathrm{CuW}$ 로 제작되었으며, $\mathrm{GaN}$ bare die의 유테틱 본딩을 위해 소프트 금도금 처리를 하였다. 그리고 $\mathrm{GaN}$ bare die는 90:10\% 비율로 합금된 $\mathrm{AuSn}$ 을 이용하여 캐리 어에 유테틱 본딩을 하였고, $\mathrm{GaN}$ bare chip과 마이크로스 트립 라인을 연결하기 위해 1 mil의 직경을 가지는 금와 이어를 이용하여 와이어 본딩 작업을 하였다. 그림 1 에서 보듯이 게이트단과 드레인단에 각각 4개의 패드가 있고, 각 패드에 2 개씩 와이어 본딩을 하여 총 8 개를 연결하였다.

\section{III. 측정 결과}

그림 8 은 제작된 $\mathrm{Ku}$-대역 전력 증폭기의 입력 전력에 따른 출력 전력, 전력 이득 및 드레인 효율 측정 결과를

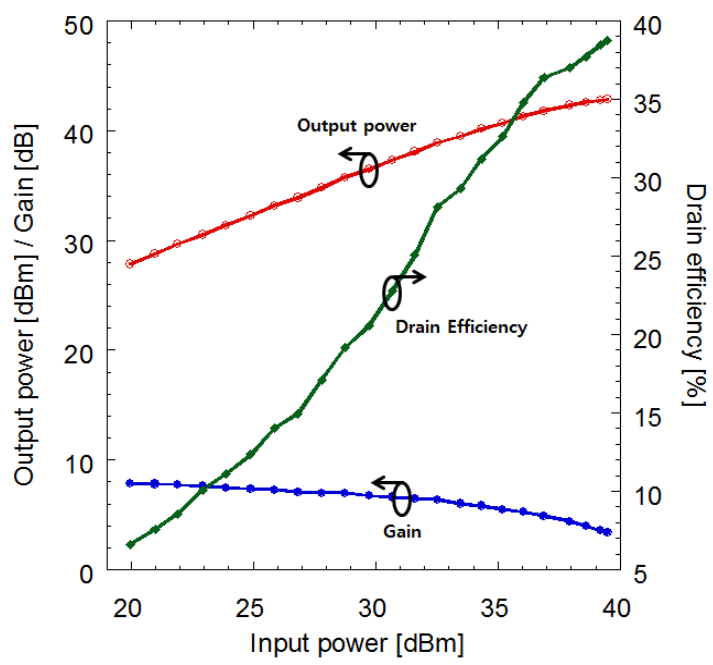

그림 8. 입력 전력에 따른 $\mathrm{Ku}-$ 대역 전력 증폭기 측정 결 과(펄스 측정)

Fig. 8. Measured results of fabricated Ku-band power amplifier as a function of input power.(pulse condition).

보여준다. $40 \mathrm{~V}$ 의 드레인 전압과 $-2.48 \mathrm{~V}$ 의 게이트 전압 을 갖는 Class $\mathrm{AB}$ 바이어스 조건에서 전력 증폭기를 구동 시켰다. 전력 증폭기 측정에 사용한 입력 신호는 펄스폭 $10 \mathrm{us,}$, 듀티 사이클 $0.01 \%$ 펄스 신호를 사용하였다. 그림 9에서 확인할 수 있듯이, 주파수 $14.8 \mathrm{GHz}$ 에서 $42.6 \mathrm{dBm}$ 의 출력전력, $37.7 \%$ 의 드레인 효율 및 $7.9 \mathrm{~dB}$ 의 선형 이 득을 얻었다.

제작된 전력 증폭기의 주파수 응답 특성은 그림 9에 나 타내었다. $14.7 \mathrm{GHz}$ 에서 $15.1 \mathrm{GHz}$ 의 대역에서 $40 \mathrm{dBm}$ 이 상의 출력 전력, $4 \mathrm{~dB}$ 이상의 전력 이득과 $23 \%$ 이상의 드레인의 효율을 얻었다.

표 2는 $14.8 \mathrm{GHz}$ 에서 펄스 duty cycle을 $0.01 \%, 0.1 \%$,

표 2. Duty cycle 가변에 따른 성능 비교

Table 2. Performance comparison of variations in duty cycle.

\begin{tabular}{|c|c|c|c|}
\hline 주파수 & Duty cycle & 출력 전력 & 드레인 효율 \\
\hline $14.8 \mathrm{GHz}$ & $0.01 \%$ & $42.6 \mathrm{dBm}$ & $37.7 \%$ \\
\hline $14.8 \mathrm{GHz}$ & $0.1 \%$ & $42.3 \mathrm{dBm}$ & $35.8 \%$ \\
\hline $14.8 \mathrm{GHz}$ & $1 \%$ & $41.6 \mathrm{dBm}$ & $35.8 \%$ \\
\hline $14.8 \mathrm{GHz}$ & $4 \%$ & $41.9 \mathrm{dBm}$ & $31.8 \%$ \\
\hline
\end{tabular}




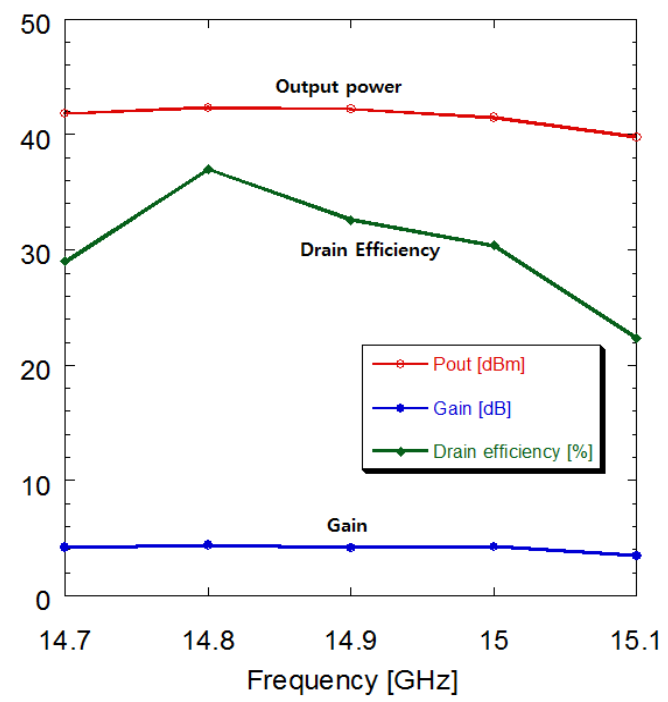

그림 9. 주파수에 따른 $\mathrm{Ku}$-대역 전력 증폭기 측정 결과 (펄스)

Fig. 9. Measured results of fabricated Ku-band power amplifier as a function of frequency(pulse condition).

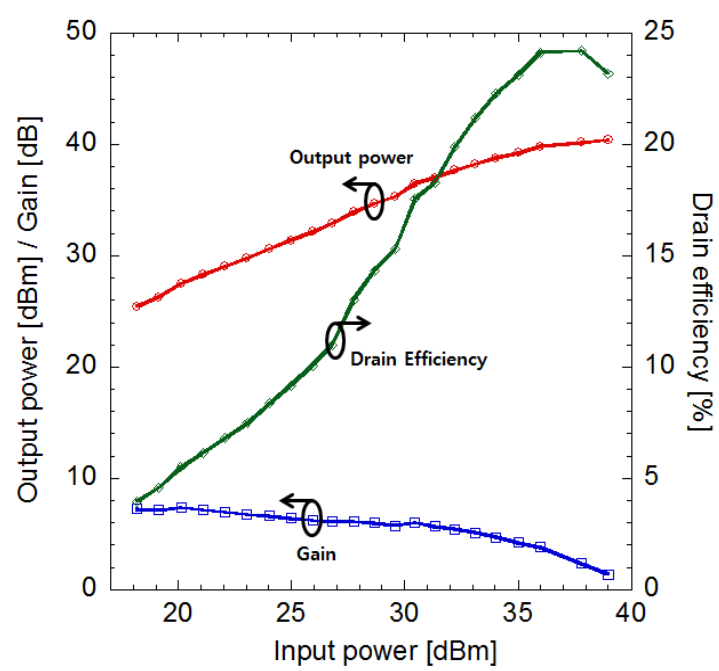

그림 10. 입력 전력에 따른 $\mathrm{Ku}-$ 대역 전력 증폭기 측정 결과 $(\mathrm{CW})$

Fig. 10. Measured results of fabricated Ku-band power amplifier as a function of input power(CW).

$1 \%, 4 \%$ 로 가변시켜 가며 전력 증폭기의 특성을 확인하 였다. 이 때, 펄스폭은 10 us로 고정을 시킨 상태에서 duty 가변을 하였다. duty가 높아지면서 $\mathrm{GaN}$ bare die의 열화

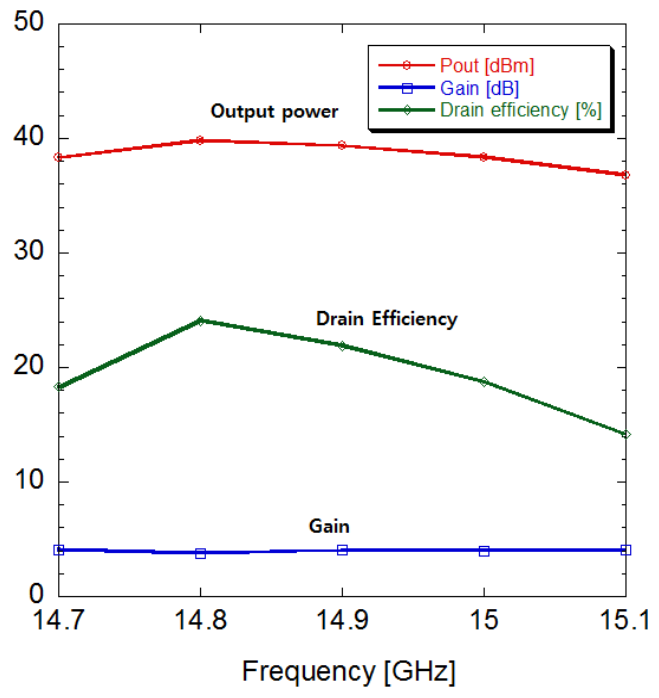

그림 11. 주파수에 따른 $\mathrm{Ku}-$ 대역 전력 증폭기 측정 결과 (CW)

Fig. 11. Measured results of fabricated low-cost Ku and power amplifier as a function of frequency(CW).

표 3. $\mathrm{Ku}-$ 대역 $\mathrm{GaN}$ 전력 증폭기 성능 비교

Table 3. Performance comparison of Ku-band $\mathrm{GaN}$ power amplifier.

\begin{tabular}{|c|c|c|c|c|c|c|}
\hline $\begin{array}{c}\text { 주파수 } \\
{[\mathrm{GHz}]}\end{array}$ & $\begin{array}{c}\text { 출력 } \\
\text { 전력 }[\mathrm{W}]\end{array}$ & $\begin{array}{c}\mathrm{PAE} \\
{[\%]}\end{array}$ & $\begin{array}{c}\text { 이득 } \\
{[\mathrm{dB}]}\end{array}$ & 크기 $\left[\mathrm{mm}^{2}\right]$ & $\begin{array}{c}\text { 운용 } \\
\text { 모드 }\end{array}$ & $\begin{array}{c}\text { 참고 } \\
\text { 문헌 }\end{array}$ \\
\hline $\mathrm{Ku}$-대역 & 62.2 & 44 & 8.5 & $9.8 \times 9.2$ & Pulse & {$[2]$} \\
\hline 13.9 & 17.7 & 36.4 & 8.7 & $16.5 \times 9.7$ & Pulse & {$[3]$} \\
\hline 14 & 100 & $\bullet$ & 8 & $\bullet$ & Pulse & {$[4]$} \\
\hline 14.25 & 34.7 & 15 & 5.3 & $11 \times 12.9$ & $\mathrm{CW}$ & {$[5]$} \\
\hline 14.8 & 18.2 & 25 & 7.9 & $16.8 \times 20$ & Pulse & 본 논문 \\
\hline
\end{tabular}

현상으로 인해 출력 전력과 드레인 효율의 특성이 저하 되는 현상을 확인할 수 있었다.

그림 10 은 $14.8 \mathrm{GHz}$ 에서 $\mathrm{CW}$ 모드에서 전력 증폭기 입 력 전력에 따른 출력 전력, 전력 이득 및 드레인 효율을 보여준다. 바이어스 조건은 펄스 측정 때와 모두 동일하 게 세팅하여 측정을 하였다. $\mathrm{Ku}$-대역 전력 증폭기 $\mathrm{CW}$ 측 정 결과로는 $39.8 \mathrm{dBm}$ 의 출력 전력, $24.1 \%$ 의 드레인 효 율과 $7.2 \mathrm{~dB}$ 선형 이득을 얻을 수 있었다. 앞의 펄스 모드 에서 얻은 출력 전력보다 $\mathrm{CW}$ 모드에서 $2.8 \mathrm{~dB}$ 낮은 출력 전력을 얻었는데, 이는 GaN bare die에서 발생하는 열로 
인해 펄스 모드에서 동작시보다 특성이 저하되는 현상을 확인하였다. 그림 11 은 $14.7 \mathrm{GHz}$ 에서 $15.1 \mathrm{GHz}$ 대역에서 의 출력 전력, 전력 이득 및 드레인 효율 특성을 보여준 다. 최대 $40 \mathrm{dBm}$ 의 출력 전력과 $4 \mathrm{~dB}$ 전력 이득 및 $24 \%$ 드레인 효율을 얻었다. 펄스 모드에서 동작시보다 열적인 문제로 인해 확연하게 특성이 저하되는 현상을 확인하 였다.

$\mathrm{Ku}$-대역 $\mathrm{GaN} \mathrm{HEMT} \mathrm{전력} \mathrm{증폭기} \mathrm{특성을} \mathrm{본} \mathrm{논문과} \mathrm{비}$ 교를 위해 표 3에 나타내었다. 본 논문이 비교 대상들에 비해 출력이 낮은 것은 단일 소자를 사용하여 전력 증폭 기 설계 및 제작을 하였기 때문이다.

\section{$\mathrm{IV}$. 결 론}

본 연구에서는 $\mathrm{GaN}$ bare die를 이용하여 $\mathrm{Ku}$-대역 전력 증폭기를 설계 및 제작하였다. 전력 증폭기 측정은 펄스 모드와 $\mathrm{CW}$ 모드에서 측정을 하였다. 펄스 모드에서 측정 한 결과로는 $14.8 \mathrm{GHz}$ 에서 $42.6 \mathrm{dBm}$ 의 출력 전력, $37.7 \%$ 드레인 효율 및 $7.9 \mathrm{~dB}$ 선형 이득을 얻었다. $\mathrm{CW}$ 모드에서 는 $39.8 \mathrm{dBm}$ 의 출력 전력, $24.1 \%$ 의 드레인 효율 및 7.2 $\mathrm{dB}$ 의 선형 이득을 확인하였다. 펄스 모드와 $\mathrm{CW}$ 모드에 서 동작을 시킬 때 성능의 차이가 있는데, $\mathrm{CW}$ 모드에서 성능의 저하가 최소화 되도록 cooling system 측면의 연구 가 필요하다. 그리고 소자를 병렬적으로 배치하여 보다 높은 출력을 얻을 수 있도록 입/출력단 정합 회로 설계 및 제작에 관한 연구가 지속적으로 이루어져야 할 것으 로 여겨진다.
김 상 훈

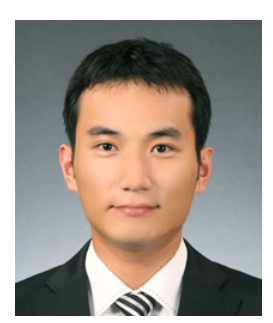

2009년 2월: 광운대학교 전파공학과 (공 학사)

2009년 9월 현재: 광운대학교 전파공학 과 석박사통합과정

[주 관심분야] RF 회로 설계, 고출력 증폭 기, TRM 등

\section{References}

[1] Aethercomm, "Gallium Nitride(GaN) Microwave transistor technology for radar applications", Microwave Journal, vol. 51, no. 1, pp. 106, Jan. 2008.

[2] K. Yamauchi, H. Noto, H. Nonomura, S. Kunugi, M. Nakayama, and Y. Hirano, "A 45\% power added efficiency, Ku-band $60 \mathrm{~W}$ GaN power amplifier", IEEE MTT$S$ International Microwave Symposium Digest, pp. 1-4, Jun. 2011.

[3] Ge Qin, Chen Xiaojuan, Luo Weijun, Yuan Tingting, Pu Yan, and Liu Jaggard, "A Ku band internally matched high power GaN HEMT amplifier with over $30 \%$ of PAE", Journal of Semiconductors, vol. 33, no. 1, Jan. 2012.

[4] H. Noto, H. Maehara, H. Uchida, M. Koyanagi, H. Utsumi, J. Nishihara, H. Otsuka, K. Yamanaka, M. Nakayama, and Y. Hirano, "X- and Ku-band internally matched GaN amplifiers with more than $100 \mathrm{~W}$ output power", Microwave Integrated Circuits Conference(EuMIC), pp. 695-698, Oct. 2012.

[5] K. Takagi, Y. Kashiwabara, K. Masuda, K. Matsushita, H. Sakurai, K. Onodera, H. Kawasaki, Y. Takada, and Y. K. Tsuda, "Ku-band AlGaN/GaN HEMT with over 30 W", Microwave Integrated Circuit Conference, 2007. EuMIC 2007. European, pp. 169-172, Oct. 2007.

김 보 기

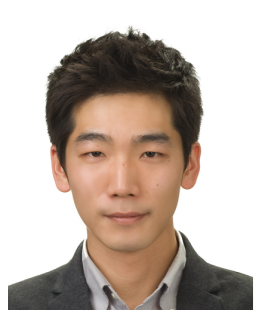

2010년 8월: 백석대학교 정보통신학과 (공학사)

2010년 9월 현재: 광운대학교 전파공학 과 석박사통합과정

[주 관심분야] RF 회로 설계, 고출력 증폭 기, 공간 결합기 등 
THE JOURNAL OF KOREAN INSTITUTE OF ELECTROMAGNETIC ENGINEERING AND SCIENCE. vol. 25, no. 6, Jun. 2014.

최 진 주

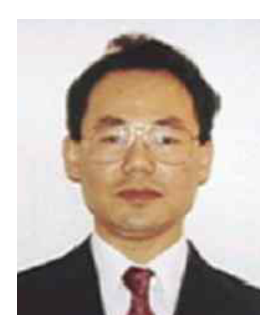

1983년 8월: 서울대학교 물리교육학과 (이학사)

1985년 8월: 미국 Georgia State University 물리학과 (이학석사)

1991년 8월: 미국 University of Michigan 핵공학과 (공학박사)

1991년 5월 1997년 8월: 미국 해군연구

소 (NRL) 연구원

1997년 9월 현재: 광운대학교 전자융합공학과 교수

[주 관심분야] RF 회로 설계, 고출력 증폭기, Vacuum Tube Amplifier 등

정 병 구

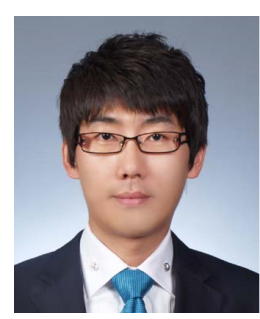

2001년 2월: 한국해양대학교 전파공학과 (공학사)

2003년 2월: 한국해양대학교 전파공학과 (공학석사)

2009년 12월: 단암시스템즈(주) 선임연구 원

2009년 12월 현재: 삼성탈레스

[주 관심분야] 초고주파 송수신기 및 시스템, DATA LINK 시스 템 설계 등

태 현 식

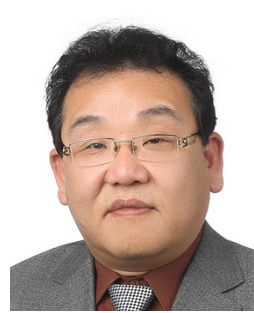

1983년 3월: 한양대학교 전자공학과 (공학 사)

1990년 5월: 동양정밀공업(주) 선임연구원 1990년 5월 현재: 삼성탈레스(주) 수석연 구원

[주 관심분야] 무선통신장비 및 통신시스 템, Data Link 시스템 설계 등 